\title{
СОСТАВ ЛЕТУЧИХ ПРОДУКТОВ, ОБРАЗУЮЩИХСЯ ПРИ ОКИСЛЕНИИ КЕРОГЕНА КУКЕРСИТА
}

\author{
(Представил О. Эйзен)
}

При получении на опытной -установке алифатических дикарбоновых кислот (ДКК) и сланцевого ростового вещества окислением концентрата керогена кукерсита $30 \%$-ной азотной кислотой и кислородом воздуха под давлением 5 ати и при температуре $140^{\circ} \mathrm{C}$ ['] продуваемый через реакторы с целью перемешивания реакционной смеси и перевода $\mathrm{NO}$ в $\mathrm{NO}_{2}$ воздух уносит вместе с парами воды и азотной кислоты органические продукты окисления керогена кукерсита, которые собираются в узле окисления в виде маслянистого слоя на поверхности конденсата.

Хотя выход этого маслянистого слоя не превышает десятой доли процента на кероген, он представляет собой интерес, во-первых, как побочный продукт, который требует или утилизации, или обезвреживания, и, во-вторых, как источник информации о структуре керогена кукерсита, так как содержит фрагменты, которые образуются при окислительной деструкции' керогена и относительно быстро удаляются из реакционной смеси.

Ранее в составе органических кислот конденсатов процесса получения ДКК методом ГЖХ были идентифицированы монокарбоновые кислоты $(\mathrm{MKK}) \mathrm{C}_{2}-\mathrm{C}_{10}$, а в маслянистом слое на поверхности конденсатов узла окисления $-\mathrm{C}_{9}-\mathrm{C}_{15}\left[{ }^{2}\right]$. Для более подробного изучения состава маслянистого слоя в данной работе он был предварительно разделен на фракции, которые анализировали. методами ГЖХ и хромато-масс-спектрометрии (ГЖХ-МС).

\section{Методика анализа}

Исходной для анализа служила основная проба маслянистого слоя $(97,5$ г), отфильтрованная от твердой фазы (непрореагировавшего керогена), отмытая дистиллированной водой от азотной кислоты и высушенная безводным сульфатом натрия. 15,9 г этой пробы разделяли на фракции: летучие с водяным паром (I и II фракции), гексановый, эфирный и ацетоновый экстракты остатка перегонки с водяным паром (табл. 1). Эфирный экстракт (ЭЭІ) из твердой фазы, содержавшейся в маслянистом слое (10,5 г), анализировали без предварительного разделения.

Количественный анализ кислот и их метиловых эфиров (МЭ) методом ГЖХ проводили на хроматографе ЛХМ8МД, модель 5 по методике [3], МЭ кислот - методом ГЖХ-МС в системе «Hewlett Packard» (хроматограф 5840 A, масс-спектрометр 5985 A, компьютер НР 1000) в условиях, аналогичных [4]. Энергия ионизирующих электронов 70 эВ. 


\section{Результаты ГЖХ и ГЖХ-МС}

. В маслянистом слое идентифицированы соединения, принадлежащие к восьми гомологическим рядам, в том числе кислоты - представители пяти гомологических рядов (табл. 2).

МКК нормального строения (H-MKK), идентифицированные в интервале $\mathrm{C}_{2}-\mathrm{C}_{28}$, преобладают по содержанию $(72,2 \%$ от исходной смеси) и сконцентрированы в I фракции летучих с водяным паром $\left(\mathrm{C}_{2}-\mathrm{C}_{18}\right)$. Гомологи выше $\mathrm{C}_{18}$ содержатся в эфирном экстракте твердой фазы и в гексановом экстракте остатка перегонки. В составе кислот преобладает пеларгоновая ( $\mathrm{C}_{9}$, рис. 1$)$.

$\alpha$-Метил-МКК представлены гомологами $\mathrm{C}_{8}-\mathrm{C}_{20}$, их выход составляет $0,6 \%$ от маслянистого слоя. Всего их образуется около $0,8 \%$ от МKK нормального строения. Характерной особенностью масс-спектров МЭ этих кислот (рис. 2) является максимальный по интенсивности пик перегруппировочного иона с $m / z 88$ [5] $\left[\mathrm{CH}_{3}-\mathrm{O}-\mathrm{C}=\mathrm{CH}\right]^{+}$, который<smiles>CCO</smiles>

образуется при разрыве молекулы $\boldsymbol{\alpha}$-метил-MKК у третичного атома углерода и переносе $\gamma$-атома водорода (перегруппировка МакЛафферти). Характеристическим для МЭ $\alpha$-метил-МКК является и ион c $m / z 101$, образующийся при простом разрыве $\beta$-связи относительно третичного атома углерода. В области тяжелых масс присутствуют пики ионов $[M-59]^{+},[M-57]^{+}$и $[M-43]^{+}$.

$\alpha, \omega$-ДКК $\mathrm{C}_{5}-\mathrm{C}_{15}$, идентифицированные в эфирном и ацетоновом экстрактах остатка после отгонки летучих с водяным паром, составляют $0,5 \%$ от маслянистого слоя.

Таблица !

Материальный баланс разделения маслянистого слоя

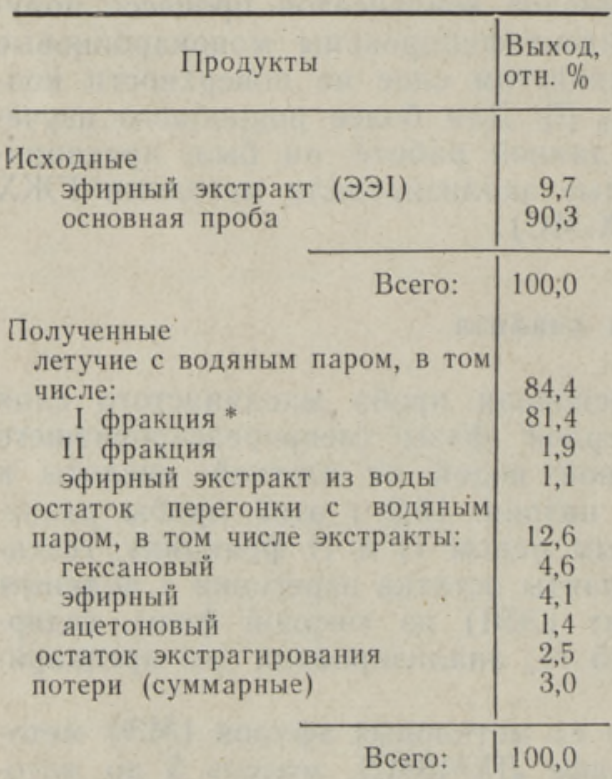

* Сюда же включен выход ЭЭІ, так как, по данным ГЖХ, компонентные составы I фракции и ЭЭ઼І идентичны.
Таблица 2

Состав маслянистого слоя и относительное распределение кислот

\begin{tabular}{|c|c|c|}
\hline Компоненты & $\begin{array}{l}\text { Co- } \\
\text { дер- } \\
\text { жа- } \\
\text { ние, } \\
\%\end{array}$ & $\begin{array}{l}\text { Относи- } \\
\text { тельное } \\
\text { распре- } \\
\text { деленне } \\
\text { кислот, \% }\end{array}$ \\
\hline $\begin{array}{l}\text { н-МКК } \mathrm{C}_{2}-\mathrm{C}_{28} \\
\alpha \text {-Метил-MKК } \mathrm{C}_{8}-\mathrm{C}_{20} \\
\alpha, \omega-Д \mathrm{~K} \mathrm{C}_{5}-\mathrm{C}_{15} \\
\text { ТКК } \mathrm{C}_{8}-\mathrm{C}_{19} \\
\text { орто-Фталевая кислота } \\
\text { н-Алканоны- } 7 \mathrm{C}_{12}-\mathrm{C}_{18} \\
\text { н-Алканы } \mathrm{C}_{15}-\mathrm{C}_{32} \\
\text { Метилалкенилцикло- } \\
\text { гексаны } \mathrm{C}_{n} \mathrm{H}_{2 n-2} \\
\quad(n=10-17) \\
\text { Нехроматографируемые } \\
\text { соединения } \\
\text { Остаток после перегонки } \\
\text { и экстракции } \\
\text { Потери } \\
\text { Неидентифицированные } \\
\text { соединения }\end{array}$ & $\begin{array}{c}72,2 \\
0,6 \\
0,5 \\
0,3 \\
0.4 \\
6,6 \\
0,5\end{array}$ & $\begin{array}{r}97,6 \\
0,8 \\
0,7 \\
0,4 \\
0,5 \\
-\end{array}$ \\
\hline Bcero & 100,0 & 100,0 \\
\hline
\end{tabular}




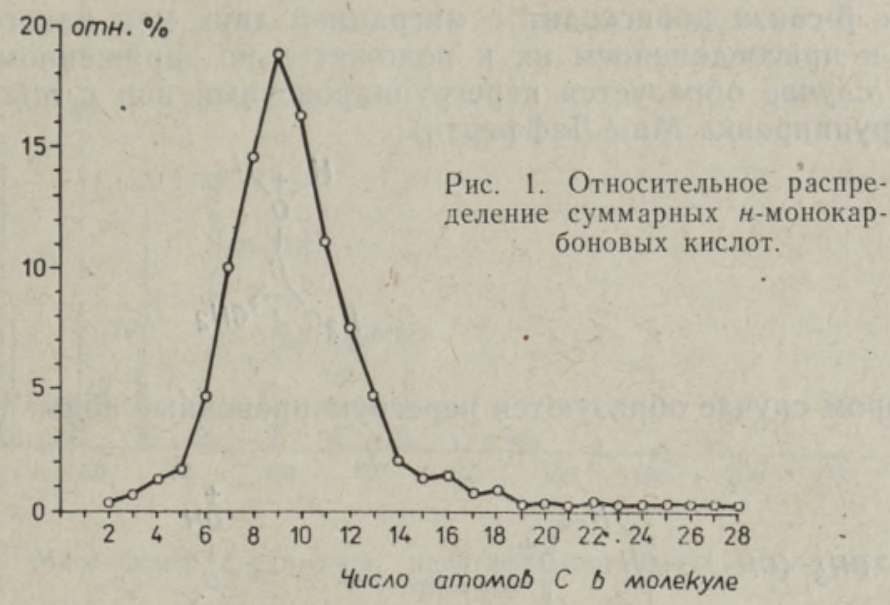

Трикарбоновые кислоты (ТKК) $\mathrm{C}_{8}-\mathrm{C}_{19}$, идентифицированные в эфир-ном экстракте остатка после отгонки летучих с водяным паром, составляют $0,3 \%$ от исходной смеси. Масс-спектры триметиловых эфиров TKК, образующихся при азотнокислотном окислении керогена кукерсита, изучены нами ранее [6].

орто-Фталевая кислота идентифицирована в эфирном и ацетоновом экстрактах остатка после перегонки с водяным паром (соответственно $10,9$ и $58,0 \%)$. Ее суммарный выход $-0,4 \%$ от исходного маслянистого слоя.

Алифатические кетоны $\mathrm{C}_{12}-\mathrm{C}_{18}$ обнаружены среди кислот I фракции летучих с водяным паром. Их выход - $6,6 \%$ от маслянистого слоя достаточно высок. По данным ГЖХ-МС, это н-алканоны-7 с преобладанием гомолога $\mathrm{C}_{16}$. Масс-спектр хроматографического пика (рис. 3 ), идентифицированного как н-гексадеканон-7, обладает особенностями фрагментации, присущими длинноцепочечным алканонам. В области тяжелых масс это достаточно интенсивный пик молекулярного иона с $m / z 240(16,7 \%)$ и пик иона $[M+1]^{+}$с $m / z 241$, образующегося в результате ионно-молекулярных процессов.

Для алканонов характерен преимущественный распад под действием электронов по $\alpha$-связи относительно карбонильной группы [7]. При этом образуются ионы $\left[\mathrm{CH}_{3}-\left(\mathrm{CH}_{2}\right)_{n}-\mathrm{C} \equiv \mathrm{O}^{+}\right.$и $\left[\mathrm{CH}_{3}-\left(\mathrm{CH}_{2}\right)_{n}\right]^{+}$. Для $н$-гексадеканона-7 (рис. 3) это ионы с $\mathrm{m} / \mathrm{z} 113,155$ и $85,127$.

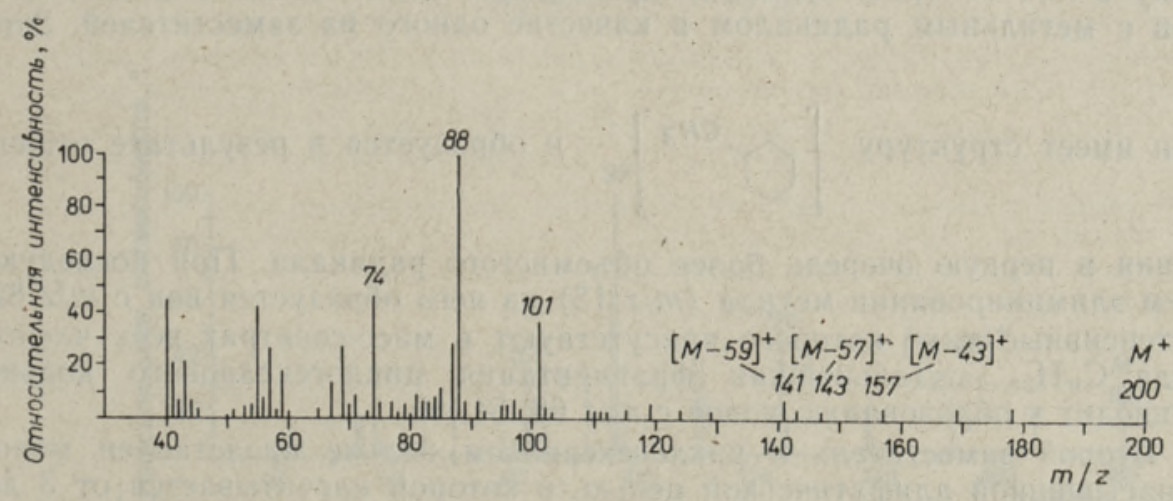

Рис, 2. Масс-спектр соединения, идентифицированного как метиловый эфир $\alpha$-метилдекановой кнслоты, $M=200$. 
Разрыв по $\beta$-связи происходит с миграцией двух или одного $\gamma$-атомов водорода и присоединением их к положительно заряженному осколку. В первом случае образуется перегруппировочный иоң с $\mathrm{m} / z 58$ (двойная перегруппировка Мак-Лафферти):<smiles>C=C1CC1[OH2+]</smiles>

Во втором случае образуются перегруппировочные ионы:<smiles>CCCCC1C=C[O+]C(CCC)CCC1</smiles>

Для гексадеканона-7 при $m=8$ и $n=2 \mathrm{~m} / z \quad 170$, при $m=5$ и $n=5-$ $m / z 128$. При элиминировании этих перегруппировочных ионов из молекулярного образуются ионы $[M-170]^{+}, m / z \quad 70$ и $[M-128]^{+}, m / z \quad 112$, диагностические при определении положения карбонильной группы в алифатической цепи (рис. 3).

Для алканонов более вероятен простой $\gamma$-разрыв, чем $\beta$ - и $\delta$-разрывы. В случае гексадеканона-7 при $\gamma$-разрыве образуются ионы с $m / z 57$ (базовый), 183, 99 и 141. Для общей картины масс-спектров алканонов характерно то, что базовый пик незначительно превышает другие интенсивные пики (рис. 3).

$\boldsymbol{\mu}$-Алканы $\mathrm{C}_{15}-\mathrm{C}_{32}$ с максимумом для $\mathrm{C}_{23}$ идентифицированы ГЖХ-МС во II фракции летучих с водяным паром кислот. Они составляют $42,2 \%$ от этой фракции, или $0,5 \%$ от маслянистого слоя. были также выделены препаративной тонкослойной хроматографией на незакрепленном слое сорбента из исходного маслянистого слоя. $\mathrm{B}$ них преобладали гомологи $\mathrm{C}_{17}$ и $\mathrm{C}_{19}$.

Производные циклогексана. В эфирном экстракте из твердой фазы и в I фракции летучих с водяным паром идентифицирован гомологический ряд $\mathrm{C}_{n} \mathrm{H}_{2 n-2}$ в интервале $\mathrm{C}_{10} \mathrm{H}_{18}-\mathrm{C}_{17} \mathrm{H}_{32}$. В масс-спектрах всех членов этого ряда максимальный по интенсивности пик соответствует иону с $m / z 97$ (рис. 4), характерному для дизамещенных циклогексанов с метильным радикалом в качестве одного из заместителей. Этот

ион имеет структуру $\left[\mathrm{C}^{\mathrm{CH}_{3}}\right]$

и образуется в результате отщеп-

ления в первую очередь более объемистого радикала. При последующем элиминировании метила $(\mathrm{m} / \mathrm{z} 15)$ из него образуется ион с $\mathrm{m} / \mathrm{z} 82$, интенсивные пики которого присутствуют в масс-спектрах всех членов ряда $\mathrm{C}_{n} \mathrm{H}_{2 n-2}$. Дальнейшая фрагментация циклогексанового кольца приводит к образованию ионов с $\mathrm{m} / z$ 68, 54,40 .

Второй заместитель в циклогексановом кольце представлен мононенасыщенной алифатической цепью, в которой насчитывается от 3 до 10 атомов углерода. Определить из масс-спектров положение двойной связи в этой цепи довольно трудно, но вполне вероятно, что у высших 


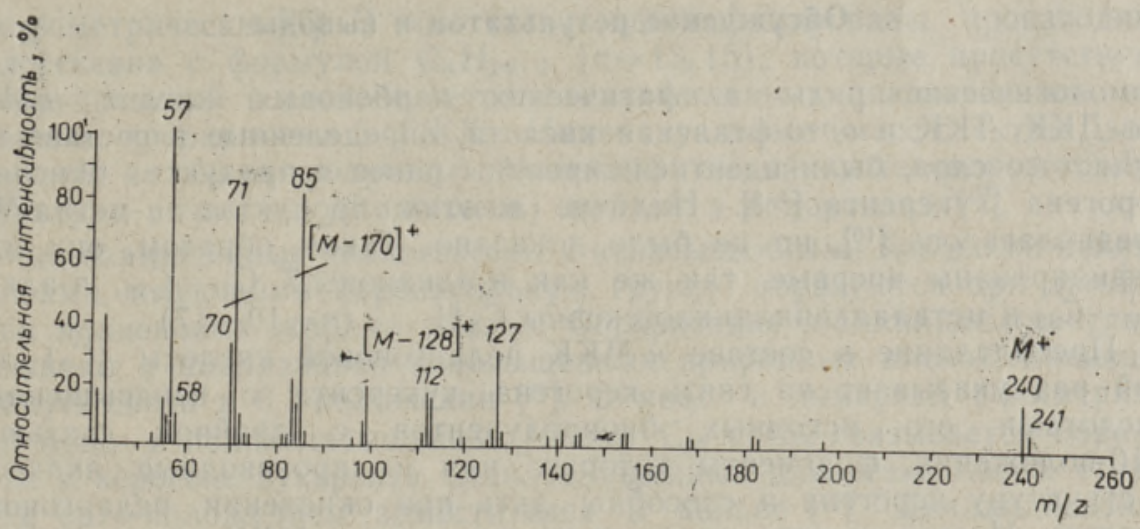

Рис. 3. Масс-спектр соединения, идентифицированного как $H$-гексадеканон-7, $M=240$.

гомологов она находится в $\gamma$-положении по отношению к циклогексановому кольцу. В этом случае характерный для мононенасыщенных углеводородов $\beta$-разрыв углерод-углеродной связй (относительно двойной связи) приводил бы к образованию ионов с $m / z 97$ и $\mathrm{M}-97$. Диссоциативная ионизация моноолефинов часто сопровождается миграцией атома водорода, с чем, возможно, связано образование ионов $[M-28]^{+}$с выбросом молекулы этилена. При перемещении двойной связи в глубь молекулы возрастает вероятность ее разрыва под действием электронов. При ее разрыве со стороны циклогексанового кольца образовался бы ион с $m / z$ 124, дающий интенсивный пик в изученных масс-спектрах членов ряда $\mathrm{C}_{n} \mathrm{H}_{2 n-2}$. Достаточно интенсивны в массспектрах пики ионов $\left[\mathrm{C}_{n} \mathrm{H}_{2 n-1}\right]^{+}$, ионов «парафинового типа». $\left[\mathrm{C}_{n} \mathrm{H}_{2 n+1}\right]^{+}$ и перегруппировочных ионов $\left[\mathrm{C}_{n} \mathrm{H}_{2 n}\right]^{+}$, которые характерны для моноолефинов.

Пик иона с $m / z 97$ преобладает по интенсивности в случае 1-метил,1-алкил- и 1-метил,3-алкилзамещенных циклогексанов [8]. Однако в случае 1,1-положения заместителей пик молекулярного иона малоинтенсивен. Например, в масс-спектре 1-метил,1-этилциклогексана он составляет $0,3 \%$ от базового [8]. Интенсивность пиков молекулярных ионов для членов ряда $\mathrm{C}_{n} \mathrm{H}_{2 n-2}$ составляет 5-17\%. Поэтому для них наиболее вероятной представляется следующая структура:
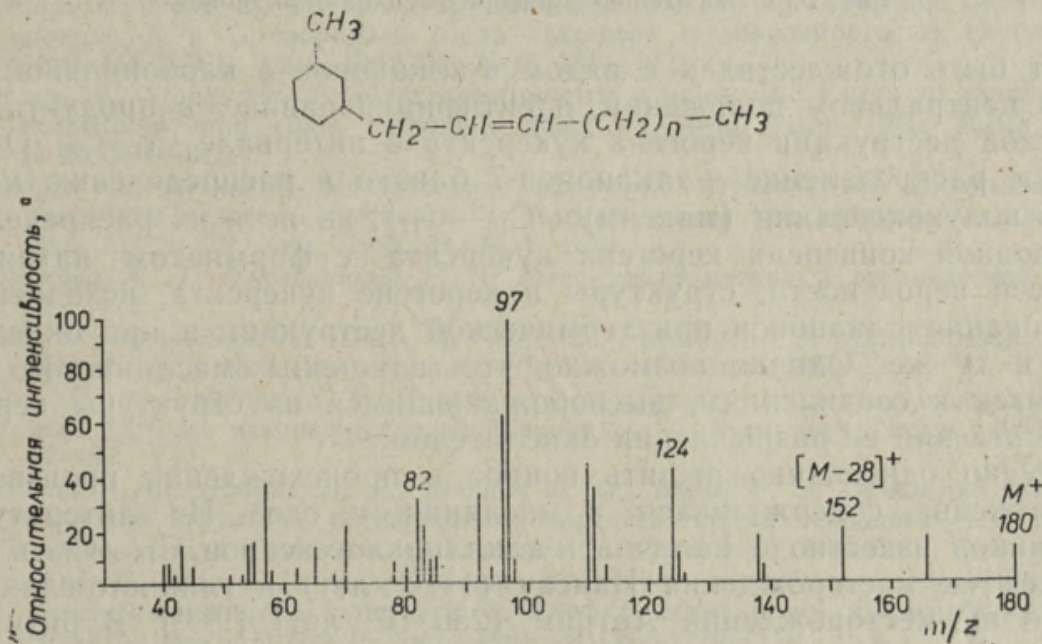

Рис. 4. Масс-спектр члена гомологического ряда $\mathrm{C}_{n} \mathrm{H}_{2 n-2}, \quad n=13$, $M=180$, 


\section{Обсуждение результатов и выводы}

Гомологические ряды алифатических карбоновых кислот $H$-МКК, $\alpha, \omega$-ДКК, ТКК и орто-фталевая кислота, определенные в составе маслянистого слоя, были идентифицированы ранее в продуктах окисления керогена кукерсита [1,9]. Наличие в этих продуктах $\alpha$-метил-МКК предполагалось [10], но не было доказано. Таким образом, они идентифицированы впервые, так же как $H$-алканоны-7 $\mathrm{C}_{12}-\mathrm{C}_{18}, \mu$-алканы $\mathrm{C}_{15}-\mathrm{C}_{32}$ и метилалкенилциклогексаны $\mathrm{C}_{n} \mathrm{H}_{2 n-2}(n=10-17)$.

Преобладание в составе $H$-MKK пеларгоновой кислоты ( $\left.\mathrm{C}_{9}\right)$ лишний раз указывает на связь керогена кукерсита с ненасыщенными кислотами его исходных биопродуцентов с двойной связью в 9,10-положении, фрагменты которых или их производные включены в структуру керогена и способны дать при окислении пеларгоновую кислоту. Низкое содержание длинноцепочечных н-MKК по сравнению с содержанием их в продуктах мягкого окисления керогена кукерсита [1'] можно объяснить их малой летучестью. ДКК, ТКК и орто-фталевал кислота перешли в маслянистый слой из конденсатов, в которые они попадают в результате капельного уноса реакционной смеси воздухом из реакторов.

н-Алканы и н-алканоны - это традиционные продукты термической деструкции керогена кукерсита, они хорошо изучены, так же как и пути их образования [12]. По длине цепи и относительному распределению $н$-алканы маслянистого слоя сходны с таковыми битумоида кукерсита $\left[{ }^{13,14}\right]$. Ряд, алканонов-7 $\mathrm{C}_{12}-\mathrm{C}_{18}$ маслянистого слоя (рис. 5)

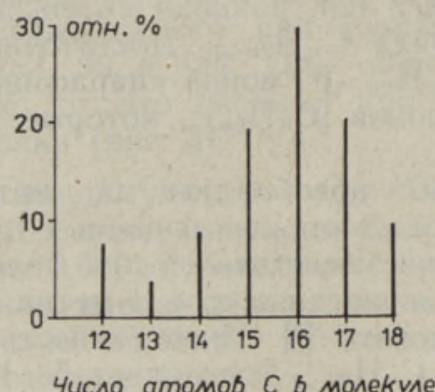

Рис. 5. Относительное распределение $н$-алканонов-7.

может быть отождествлен с рядом н-алканонов с карбонильной группой в центральном положении, идентифицированных в продуктах термической деструкции керогена кукерсита в интервале $\mathrm{C}_{6}-\mathrm{C}_{23}$. Относительное распределение $н$-алканонов-7 близко к распределению нонов полукоксования (максимум $\mathrm{C}_{13}-\mathrm{C}_{17}$ ), но не к их распределению при водной конверсии керогена кукерсита с формиатом натрия $\left[{ }^{12}\right]$. По всей вероятности, структуры в керогене кукерсита, исходные для образования алканонов при термической деструкции и при окислении, одни и те же. Однако возможно, что алканоны маслянистого слоя относятся к соединениям, высвобождающимся из структуры керогена кукерсита при ее разрыхлении окислителем.

Трудно однозначно решить вопрос о происхождении производных циклогексана, содержащихся в маслянистом слое. Из литературных источников известно о наличии $\boldsymbol{H}$-алкилциклогексанов $\mathrm{C}_{15}-\mathrm{C}_{19}$ в древних нефтях месторождения Нансач $\left(1 \cdot 10^{9}\right.$ лет) и глинисто-сланцевой породе из месторождения Антрим $\left(256 \cdot 10^{6}\right.$ лет) $\left[{ }^{15,16}\right]$. В битумоиде сланца Грин-Ривер найдено более 20 моноциклических углеводородов $\left(\mathrm{C}_{13}-\mathrm{C}_{24}\right.$, кроме $\left.\mathrm{C}_{17}\right)$, структура которых установлена масс- 
спектрометрически [17]. В том числе идентифицированы производные циклогексана с формулой $\mathrm{C}_{n} \mathrm{H}_{2 n-2}(n=13,15)$, которые присутствуют в виде примесей в составе тетраметилзамещенных циклогексанов, выделенных препаративной ГЖХ. Индивидуальные масс-спектры этих примесей не были получены. Моноциклический углеводород $\mathrm{C}_{20} \mathrm{H}_{40}$ (структура точно не установлена) найден в водорослях [18].

Многозамещенные циклогексены с ненасыщенными боковыми цепями и цепями, имеющими карбоксильную группу, образуются при димеризации полиеновых жирных кислот. Образование $н$-алкилциклогексанов связывают с циклизацией ненасыщенных природных кислот, имеющих двойную связь в 6,7-положении [16]. С моно- и димерной полимеризацией моно- и полиненасыщенных кислот $\mathrm{C}_{16}$ и $\mathrm{C}_{18}$ связывается образование в ке̊рогене кукерсита алкилзамещенных циклогексановых структур с орто-положением заместителей в кольце [19]. Диалкилбензолы смолы полукоксования кукерсита также содержат заместители в орто-положении [12]. Поэтому вызывает сомнение их генетическая связь с производными циклогексана, идентифицированными в данной работе, для которых предполагается мета-положение заместителей.

Таким образом, установлено, что органические продукты, уносимые воздухом из реакционной смеси, образующейся при окислении керогена кукерсита азотной кислотой, на $72,2 \%$ состоят из монокарбоновых кислот нормального строения, которые и определяют сырьевые качества исследованного продукта. Три гомологических ряда соединений, содержащихся в маслянистом слое в малых количествах, в продуктах окисления керогена кукерсита идентифицированы впервые.

\section{Л ИТ Е РА Т У А}

1. Фомина А. С., Вески Р. Э., Мянник А. О. Химическая переработка сланцакукерсита на диметиловые эфиры дикарбоновых кислот и сланцевое ростовое вещество. Таллин, 1984 (в печати).

2. Бондарь E., Вески P., Фомина A. Состав монокарбоновых кислот, сопутствующих производству дикарбоновых кислот из керогена кукерсита. - Изв. АН ЭССР. Хим. Геол., 1972, 21, № 2, 129-132.

3. Бондарь $E$. Количественный анализ многокомпонентных смесей органических кислот. - Изв. АН ЭССР. Хим., 1979, 28, № 4, 241-245.

4. Бондарь E., Палу B., Вески Р. Об изменении состава органических кислот биту моидов А и С сапропеля озера Лахепера в зависимости от глубнны. Изв. АН ЭССР. Хим., 1982, 31, № 3, 181-192.

5. Ryhage, R., Stenhagen, E. Mass spectrometric studies. IV. Esters of monomethylsubstituted long chain carboxylic acids. - Arkiv kemi, 1960, Häfte 4, 15, N 26, 291-315.

6. Бондарь E., Вески P. Исследование продуктов ступенчатого азотнокислотного окисления керогена кукерсита. 4. Алифатические трикарбоновые кислоты. Изв. АН ЭССР. Хим., 1982, 31, № 1, 1-9.

7. Полякова A. A., Хмельницкий P. A. Масс-спектрометрия в органической химии. M., 1972.

8. Atlas of Mass Spectral Data, 3. (Ed. E. Stenhagen, S. Abrahamsson, F. W, McLafferty.) New York-London-Sydney-Toronto, 1969.

9. Вески P. Э., Бондарь Е. Б. Сравнительное изучение продуктов окисления твердых горючих ископаемых разной природы. - Хим. тверд. топл., 1981, № 4, $47-56$.

10. Фомина А. С., Побуль Л. Я., Мянник А. О., Вески Р. Э. Окисленне как метод изучения структуры органического вещества горючих сланцев, - В кн.: Горючие сланцы (Геохимия и литология). Таллин, 1975, 36-41.

1.1. Бондарь E., Вески P. Исследование продуктов ступенчатого азотнокислотного окисления керогена кукерсита. 3. Алифатические моно- и дикарбоновые кислоты. - Изв. АН ЭССР. Хим., 1981, 30, № 3, 172-179.

12. Klesment, I., Nappa, L. Investigation of the structure of Estonian oil shale kukersite by conversion in aqueous suspension. - Fuel, 1980, 59, N 2, 117-122. 
13. Уров К. Э. Сравнительная характеристика спиртобензольного и эфирного экстрактов керогена кукерсита. - Хим. тверд. топл., 1975, № 5, 66-67.

14. Пайс Р., Клесмент Н., Побуль Л. Углеводороды и кислородные соединения в битумоиде сланца-кукерсита. - Изв. АН ЭССР. Хим., 1979, 28, № 2, $182-190$.

15. Джонс Р. Б. Химическое доказательство докембрийской жизни на Австралийском материке. - В кн.: Органическая геохимия, вып. 2. М., 1970, 105-118.

16. Johns, R. B., Belsky, T., McCarthy, E. D., Burlingame, A. L., Haug, P., Schnoes, H. K., Richter, W., Calvin, M. The organic geochemistry of ancient sediments. - Geochim. et Cosmochim. Acta, 1966, 30, N 12, 1191-1222.

17. Anders, D. E., Robinson, W. E. Cycloalkane constituents of the bitumen from Green River shale. - Geochim. et Cosmochim. Acta, 1971, 35, N 7, 661-678.

18. Cadroso, J., Brooks, P. W., Eglinton, G., Goodfellow, R., Maxwell, J. R. Lipids of recently-deposited algal mats at Laguna Mormona, Baja California. - In: Environmental Biogeochemistry, I. Ann Arbor, 1976, 149-174.

19. Клесмент И. Р. Об образовании парафинов и олефинов при низкотемпературном разложении эстонского горючего сланца-кукерсита. - Хим. тверд. топл., 1973, № $3,112-118$.

Институт химии

Академии наук Эстонской ССР
Поступила в редакцию $21 /$ III 1983

Jevgenia BONDAR, R. VESKI

\section{KUKERSIIDI KEROGEENI OKSODEERIMISEL TEKKIVATE LENDUVATE ORGAANILISTE PRODUKTIDE KOOSTIS}

Artiklis on esitatud dikarboksüülhapete saamise katseseadme oksüdatsioonireaktorite kaskaadist läbipuhutud õhuga kaasa kandunud ja vastuvõtjas õhukese ölika kihina kondenseerunud orgaaniliste produktide analüüsi tulemused. Gaasi-vedelikukromatograafia ja kromatomassispektromeetria abil määrati sirge ahelaga küllastunud monokarboksüül$\left(\mathrm{C}_{2}-\mathrm{C}_{28}\right)$ ja $\alpha$-metüülmonokarboksüülhapped $\left(\mathrm{C}_{8}-\mathrm{C}_{20}\right)$, alkanoonid-7 $\left(\mathrm{C}_{12}-\mathrm{C}_{18}\right)$, $n$-alkaanid $\left(\mathrm{C}_{15}-\mathrm{C}_{32}\right)$, tsüklilistest ühenditest metüülalkenüültsükloheksaanid $\mathrm{C}_{n} \mathrm{H}_{2 n-2}$ $(n=10-17)$. jt. ühendid.

\section{Eugenia BONDAR, R. VESKI}

\section{THE COMPOSITION OF VOLATILE OXIDATIVE PRODUCTS OF KUKERSITE KEROGEN}

By the use of gas-liquid chromatography and computerized gas chromatography-mass spectrometry the saturated normal $\left(\mathrm{C}_{2}-\mathrm{C}_{28}\right.$, max. $\left.\mathrm{C}_{9}\right)$ and $\alpha$-niethylmonocarboxylic acids $\left(\mathrm{C}_{8}-\mathrm{C}_{20}\right)$, alkanones-7 $\left(\mathrm{C}_{12}-\mathrm{C}_{18}\right)$, n-alkanes $\left(\mathrm{C}_{15}-\mathrm{C}_{32}\right)$, methylalkenylcyclohexanes $\mathrm{C}_{n} \mathrm{H}_{2 n-2}(n=10-17)$ and other products were determined, with $n$-monocarboxylic acids as a major product $(72.2 \%$ of the oily layer on condensate), in addition to the pilot production of dicarboxylic acids and plant growth activators from kukersite shale kerogen by the nitric acid-air oxydation process $\left(30 \% \mathrm{HNO}_{3}, 5 \mathrm{~atm}, 140^{\circ} \mathrm{C}\right.$, air blowing). The above components, except $n$-monocarboxylic acids, were identified in the oxidative destruction products of kukersite kerogen for the very first time. 